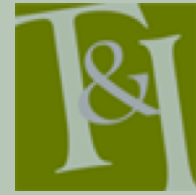

The International Journal for Translation \& Interpreting Research

trans-int.org

\title{
Translation and visual cues: Towards creating a road map for limited English speakers to access translated Internet surveys in the United States
}

\author{
Mandy Sha \\ Independent Consultant \\ mandy@mandysha.com
Y. Patrick Hsieh
RTI International
yph@rti.org \\ Patricia Goerman
U.S.Census Bureau
patricia.l.goerman@census.gov
}

DOI: 10.12807/ti.110202.2018.a10

\begin{abstract}
This study seeks to provide a starting point in the survey translation and user experience literatures about facilitating entry to online survey questionnaires among limited English speakers in the United States. We present results from an assessment of prototype materials with limited English speakers: prenotification materials, survey entry pages, and informational web pages. We found that combining translation with common website functionality visual cues (tabs, hyperlinks, drop-down menus, and URLs) can help limited English-speaking individuals improve their experience using and accessing entry pages and informational web pages for government surveys. We also provide recommendations for continued research to develop translations and visual cues that are visible, clear, and linguistically and culturally appropriate. The ultimate goal is increased inclusion and accessability for hard-to-reach populations in online Federal surveys in the United States.
\end{abstract}

Keywords: Translated internet surveys, website functionality visual cues, web pages, prenotification materials, accessibility, usability

\section{Introduction}

As many large United States (U.S.) government surveys are moving toward online survey data collection, barriers to survey participation may include low digital literacy and limited access to the Internet, in addition to people being busy or not interested. Limited English-speaking survey respondents also experience language barriers, which are usually addressed by the provision of translated survey questionnaires in participants' native languages. However, something that can be a "hidden barrier" to survey participation is how these survey respondents can actually access translated Internet survey questionnaires. To become aware that the translated survey questionnaire exists, they must rely on government information and services, such as prenotification mailings, informational web pages, and survey entry pages. It stands to reason that if limited English-speaking 
survey respondents could quickly and easily understand and locate information about the survey and the survey entry page, it would facilitate their login to the survey questionnaire and increase their likelihood of online survey participation.

While some U.S. Federal agencies are spending a great deal of resources to translate and pretest survey questionnaires in multiple languages, it is unclear how the translation effort can best be extended to addressing the point of entry to online surveys themselves. Understanding the possible "hidden barriers" to usability and access to translated online materials will inform strategies to increase Internet survey response among limited English speakers. It is extremely important to include limited English speakers in large Federal surveys to produce accurate population estimates and in order to have accurate information about the full U.S. population. Limited English speakers constitute a sizable portion of the U.S. population. The American Community Survey reported that $22 \%$ of the 60.6 million people aged 5 and older who spoke a language other than English at home also spoke limited English (they spoke English "not well" or "not very well") (Ryan, 2013). Among them are Asian Americans and Pacific Islanders (AAPI), one in three of whom are Limited English Proficient (LEP) individuals according to the White House Initiative on Asian Americans and Pacific Islanders. Asians referring to persons self-identified as having origins in "any of the original peoples of the Far East, Southeast Asia, or the Indian subcontinent" (see details in U.S. Census Bureau's Glossary) - are the fastest growing racial group in the United States (Census Bureau, 2016). Improving their coverage in Federal statistics must involve improving the survey participation of the limited Englishspeaking segment of this group. As many survey operations are moving to online modes of administration for various reasons including cost reduction, the online mode's impact on survey response among limited English speakers remains unclear. What is clear is that ensuring accessible translated Internet surveys is the prerequisite to survey participation. This paper focuses on government information and services that can guide respondents to the translated survey questionnaire login/start pages. Our analysis focuses on the role of translation and visual cues in accessing these types of pages.

In this paper, we discuss results from an assessment of pre-notification mailings, prototype survey entry pages, and informational web pages with 45 limited English-speaking research participants in the U.S. who are of Asian origins. We provide descriptive statistics to summarize participants' interactions with these materials and also describe how they engaged with the translation and visual cues presented in the materials.

\section{Literature review and background}

Functionalist approaches to translation aim to achieve a translation's explicit or implicit skopos (purpose) (Reiss \& Vermeer, 1984) and the intended communicative function (Nord, 1997). For example, researchers from Auckland University of Technology (Crezee, Teng \& Burn, 2017; Teng, Burn \& Crezee, 2018) have applied functional translation theories to evaluate whether functional equivalence was achieved when interpreting specific legal questions from English to Chinese. They found that renditions in Chinese (e.g. syntactical structures) by student interpreters might initially appear to be "natural" and "comparable"; however, achieving pragmatic functions actually requires language-specific feedback, deliberate practice and training, and evaluations by assessors proficient in both the source and target languages. In general, the survey translation literature reflects functionalist approaches. Harkness (2003) has proposed a 
comprehensive model called TRAPD - Translation, Review, Adjudication, Pretesting, and Documentation - to be implemented in the survey translation lifecycle. Behr and Shishido (2016) and Harkness (2010) have advocated that survey questionnaires and materials should be produced by a team of language, survey, and subject matter experts to cover both linguistic and measurement perspectives (also see Goerman et al., 2010a, 2010b; Sha \& Pan, 2013 on empirical assessment).

This paper looks at access to Internet survey questionnaire translations among limited English speakers in the U.S. This type of translation might be considered to come under the definition of Community Translation (Taibi \& Ozolins, 2016). According to Taibi and Ozolins, community translations - such as those enabling communications between governments and the linguistic minority communities they serve - must reflect the functional needs of the recipients and the sociocultural factors that affect their comprehension. When people who rely on written language services are afforded access to information, it can empower them to be more integrated in the society. In the case of Internet survey questionnaires, translations need to cover the survey questions themselves, instructions, and website functionalities used by survey respondents. After a translation is made available for use on the Internet, a large question is how limited English-speaking individuals can be made aware that translated content exists and then easily access it. There are a number of ways that a limited Englishspeaking person could access a non-English language government survey, for example: 1) by typing in the URL directly, 2) by clicking on a hyperlink in an email or on social media, or 3 ) by using a search engine (if the survey or its entry page is enabled to appear in search results). These steps may lead directly to the login/start page (which often asks for a username and password) to start the survey questionnaire, or to a survey entry page containing a path that leads to the actual survey. When an entry page is used, survey respondents must follow navigational cues. Common survey entry page designs use hyperlinks, tabs, buttons, or drop-down menus to guide respondents to translated content, but the entry page itself may or may not display non-English wording.

There are three relevant initiatives in the United States that have shaped the issue of access to U.S. government information and services on the Internet for limited English-speaking people: 1) the e-government initiative 2) Section 508 (part of a Federal law that emphasizes the functional compatibility of egovernment for people with disabilities), and 3) Executive Order 13166 Improving Access to Services for Persons with Limited English Proficiency (LEP). In the United States, the E-Government Act of 2002 was signed into law to guide government agencies in providing access to electronic government resources, including websites for information and services to their constituents (Aldrich, Bertot, \& McClure, 2002). Scholarly literature on e-government has primarily concentrated on evaluating the readiness and effectiveness of electronic services. Scholars have put forth a user-centred evaluation framework that focuses on the needs of those using e-government services and their behaviours (e.g. Bertot \& Jaeger, 2006; Verdegem \& Verleye, 2009). The focus on usability and accessibility of e-government originated from the user-centered design approach from user experience research (UX) in the information and computer sciences field. Yet, the current literature overlooks the fact that users with disadvantaged socioeconomic status may not be able to go online easily and utilize electronic government services at all (Hargittai \& Hsieh, 2013; Helbig, Gil-García, \& Ferro, 2009; West, MD, 2006; Zacradoolas, Blanco \& Boyer, 2002). U.S. researchers studying e-government have mainly focused on people with physical disabilities 
as mandated by Section 508 of the Rehabilitation Act (Jaeger, 2006; Olalere \& Lazar, 2011; Selden \& Orenstein, 2011).

There is little systematic research into what the e-government needs are among US residents with limited English proficiency. Neuhauser, Rothschild, \& Rodríguez (2007) assessed the U.S. government's food guide website MyPyramid.gov ${ }^{l}$ and identified its literacy, cultural and linguistic factors. In theory, this type of assessment could be done with translated version of the website, but the authors were unable to do so because its Spanish language site was not complete at the time they were conducting the assessment.

The content of Federal government websites in the United States is often made available in non-English languages. For example, the official website of the United States government (usa.gov) maintains a Spanish language site. The Department of Homeland Security's public service website Ready hosts a series of web pages in 13 languages to provide online resources about emergency preparedness (ready.gov/languages). Each website has its own design convention. Additional examples are as follows:

- On uscis.gov, a hyperlink Español (i.e. 'Spanish') appears as part of the homepage banner at the top of the screen.

- On ssa.gov, the top menu bar includes the symbol of a globe next to the uppercase English language word LANGUAGES; clicking on it takes the user to a new page ssa.gov/site/languages/en/ that includes hyperlinks leading to information in 19 languages.

- On census.gov/2010census (the web page for the 2010 U.S. Census), a drop-down menu allowed visitors to select from more than 40 languages for information on the census. Each language was listed in its native language characters and in English, e.g.: 中文 Chinese.

These agencies are guided by Executive Order 13166 that requires U.S. Federal agencies to assess the need for services and "develop and implement a system to provide those services so limited English-speaking persons can have meaningful access to them." The Executive Order does not require that Federal agencies translate entire websites, but only the "vital information" (lep.gov). Individual government agencies are left to determine what kind of information is "vital" and to what extent non-English speakers might need to access it.

While prior translation literature provides a framework about how to translate survey questions and materials, getting survey participants to notice and follow the translation to begin the survey poses a fundamental challenge for online survey data collection. To fill this gap, we examine how translation and visual cues on prenotification mailings, survey entry pages, and informational web pages could facilitate entry to survey questionnaires. The findings and implications also help to expand the line of research about the e-government needs of limited English-speaking individuals, specifically their usability and access when using U.S. government information and resources on the Internet.

\footnotetext{
${ }^{1}$ MyPyramid.gov is no longer operational because it was replaced by more recent food guidance.
} 


\section{Research methods}

The assessment study we discuss in this paper was a small exploratory research add-on to a larger research study to design and pretest translated draft survey questionnaires and materials for use in a large government survey operation. The assessment design reflected survey questionnaire pretesting and usability testing literature that produced qualitative insights and descriptive statistics. To recruit participants for pretesting assessments, Willis $(2005$; 2015) has indicated that the most frequently used method is quota sampling. This method does not focus on statistical representation in the findings. Instead, it focuses on the "variation across a range of characteristics" among the participants and representation is achieved by interviewing "the greatest cross-section of the population as is possible, in order to identify a wide range of problems" (p. 140). Willis also suggested that a 1-hour interview is a reasonable duration and conducting more than 12-15 interviews is seldom necessary to detect problems in the materials. Geisen and Bergstrom (2017) defined survey usability testing as the study of whether and how users can operate the product being tested (in this study, the participants were the users and the "product" was the materials). Like Willis, they also indicate that a small non-probability sample works well for this type of assessment because in most cases it is unnecessary to generalize usability problems to the entire population.

Languages, locations, and the number, length, and locations of the assessments. We conducted 45 assessments of draft survey web pages and materials in one-on-one interviews, 15 each in Chinese, Korean, and Vietnamese in April and May of 2015 in Illinois, North Carolina, California, and Washington D.C. in the United States. These three languages were chosen because they were the most frequently spoken Asian languages in the United States (Ryan 2013). This assessment took 5 to 10 minutes toward the end of the main study interview, so the research participants spent on average 60 minutes in total with the interviewer in a private location chosen by the participants, such as in a public library study room.

Participants and interviewers. There were 45 adult participants, 15 each for Chinese, Korean, and Vietnamese interviews. Language specialists of the respective languages were trained as interviewers who conducted the assessments. Using the quota sampling technique, we recruited and selected participants to achieve a range of ages, genders, year of entry into the U.S., and number of residents in the household. Together the research participants represented a diverse cross-section of characteristics as recommended in the literature (Willis 2005 ; 2015). Because this assessment was part of a larger study that had its own recruitment criteria, respondents were not systematically screened for prior survey experience and proficiency with the Internet and this limitation is acknowledged in the Conclusion and Limitations section below. To be eligible for the study, participants were screened for their native and English language proficiency, i.e. they self-identified to speak, read and write Chinese, Korean, or Vietnamese well or very well (their dominant language) but also spoke little or no English ${ }^{2}$. The exceptions were six individuals (two for each language) who self-identified that they spoke English well but considered their native language to be their dominant language; they had been recruited primarily to test a different part of the survey in

\footnotetext{
${ }^{2}$ Self-identification of English language proficiency and language spoken at home are survey questions used by the U.S. Census Bureau to measure language use in the United States, see Ryan, C. (August 2013) for more details. We used similar questions to ask the participants to self-identify their language ability in the assessment.
} 
the larger study. For the purpose of this research, we included them in our group with limited English-speaking research participants.

Procedures. The materials included in this analysis are described in detail in the following section. The procedures for the assessment are as follows: The research participants first reviewed a prenotification mailing that included a multilingual postcard. It provided the URL of a primary survey entry page. Next, the participants looked at printed, paper versions of mock survey entry pages and informational pages that had the same colour and screen displays as if they were live web pages. To demonstrate how they would get to the survey questionnaire or look for translated content, the participants showed the researchers where they would click on the hyperlinks on these web pages by pointing a finger at the spot on the paper mock up. While the interviewers knew that the survey was available in the participants' native languages, this information was not shared with the participants. Interviewers watched to see if participants would be able to locate it themselves. The materials were translated by a commercial translation company hired by the study sponsor and were reviewed by our team of language and survey experts for their accuracy.

Analysis. All assessments were first summarized by the interviewers using video and audio recordings of the interviews and then the researchers coded them according to the participants' assessment of the postcard and web pages. The coding scheme focused on whether participants recognized common website functionality visual cues, such as URLs, hyperlinks, tabs, and drop-down menus. Researchers also coded types of navigation strategies used by respondents, and their engagement with content in both English and the respective target language.

\subsection{Multilingual postcard and web pages}

As seen in Figure 1, the draft postcard that was part of the prenotification mailing contained a message in English asking respondents to participate in a test version of a government survey. The URL of the survey entry page and a toll-free number were printed below the message, which was translated in five languages. After reviewing the postcard, the participants discussed what language they would expect to see when they went to the URL.

Before starting to fill out the survey questionnaire via a login page, the participants had to begin the process from a survey entry page. For our research design, there were three entry options as described below. Identifying details about the government sponsor and survey name are redacted in the Figures. In the descriptions, we refer to the name of the survey as survey name.

The mock primary survey entry page is shown in Figure 2 (referred to as "web page 1"). It was in English and provided a link to the login screen of the English language survey (where the survey respondent could enter a username and password to start answering the survey questions). It also provided multilingual hyperlinks to language-specific survey entry pages. The English hyperlink said Begin Survey Name. The multilingual hyperlinks indicated the survey name only and were displayed in their native language characters. The wording did not mention to "begin" the survey questionnaire because clicking on the hyperlinks would not lead to the login screen of the survey. It led to a language-specific survey entry page that was then linked to the login screen of the language-specific survey (Figure 3). In addition, a standard warning statement appeared on the bottom of the survey entry page. 
You are

to respond to the 2015

You can go online or call.

\section{https://respond.}

\section{$1-800-555$}

Español: Según las '....... vigentes, usted está

2015. Puede hacerlo en internet o llamar por teléfono.

中文:

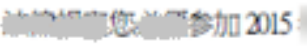

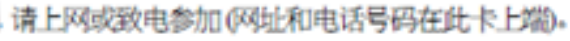

한국어:연방법에 따라 귀하는 2015

시범 조사에 참여할 의무가 있습니다. 위의 웹사이트를 방문하거나 전화하셔서 조사에 참여해 주십시오.

tiếng Việt: Luật pháp yêu cà̀u quý vị phải trả lời Thử Nghiệm 2015. Quývị œ thế trá lợi trển mạng hođ̆c gọi điện. (Địa chi trang mạng và sô điện thoại được ghi ở phia trên đâu trang.)

Русский: Согласно закону Вы обязаны принять участие в 2015 .. Это можно сделать на сайте или по телефону.

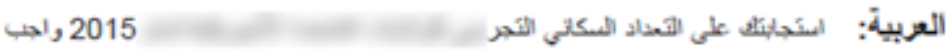

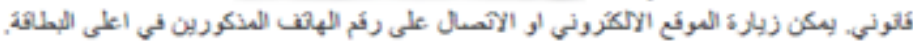

Figure 1. Multilingual postcard with a URL to the survey entry page. (Identifying information about the government sponsor and survey name are redacted for this paper)

\section{5}

Welcome to the 2015

You will need the materials we mailed to you in order to start. All the information that you provide will remain confidential.

\section{Begin the 2015}

Para completer en español, haga clic aquí

** WARNING **

You have accessed a UNITED STATES GOVERNMENT computer. Use of this computer without authorization or for purposes for which authorization has not been extended is a violation of Federal law and car be punished with fines or imprisonment (PUBLIC LAW 99-474). System usage may be monitored, recorded, and subject to audit. Any information you enter into this system may be used by for statistical purposes, including but not limited to improving the efficiency of our data collection programs. For information regarding the use of this system, and how your privacy is protected, visit our online privacy webpage at http:// /privacy/privacy_policy/. Use of this system indicates consent to the collection, monitoring, recording, and use of information provided inside this system.

Accessibility Privacy Securty

Figure 2. Primary survey entry page ("Web page 1")

Figure 3 depicts the language-specific survey entry page in Korean (Referred to as "web page 2"). All text from the English survey entry page was translated 
and included here. In contrast to the English entry page, which had multiple links in different languages and the English survey entry link, there were only two hyperlinks on the mock Korean page - one to go to the login screen of the Korean language survey, and one to go back to the primary survey entry page.

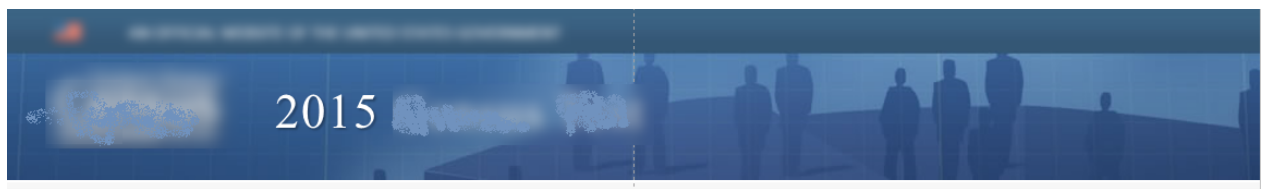

2015

조사 참여를 위해서 인구조사국에서 받은 우편물을 준비해 주십시오. 귀하가 답하신 내용은 철저히 보호됩니다.

$\underline{2015}$

To complete in English, click here

**인터넷 시스템 이용에 대한 중요 공지**

귀하는 미국 연방 정부의 컴퓨터에 접속하셨습니다. 귀하의 접속은 2015 시범조사 참여를 위해 승인되었습니다. 귀하가 이 컴퓨터에 입력하시는 모든 정보는 인구조사국에 의해 프로그램의 효율성 향상 등 통계 목적으로 사용될 수 있습니다. 본 시스템의 이용 및 귀하의 개인 정보가 어떻게 보호되는지에 대해 자세히 알고 싶으시다면, 인터넷 개인 정보 보호에 관련된 인터넷 사이트 http:// /privacy/privacy policy/ 를 참고해 주십시오. 본 시스템을 이용한다는 것은 이 시스템을 통해 제공하시는 정보의 수집, 모니터링, 기록 및 이용에 귀하가 동의하신다는 것으로 간주됩니다.

이 컴프터 시스템의 이용음 모니터링, 기롤 및 감사의 대상이 될 수 있슴니다. 이 컴프터를 정상젔인 승이었이 사용하거나 허용 범위 를 벗어나 ㅁㅗㅗ적으로 사용하느 것으 여방법을 위바하는 것이며, 벌금 또는 금고혐의 처벌을 밞을 수 있슴니다. (공법 제 99조 474항)

Figure 3. Language-specific survey entry page: Korean ("Web page 2")

For this research, we also designed an informational web page in each language, which contained general information about the survey. Figure 4 shows the informational web page (referred to as "web page 3") in Vietnamese. On the bottom of the screen is a hyperlink to the Vietnamese survey entry page and it is circled in Figure 4.
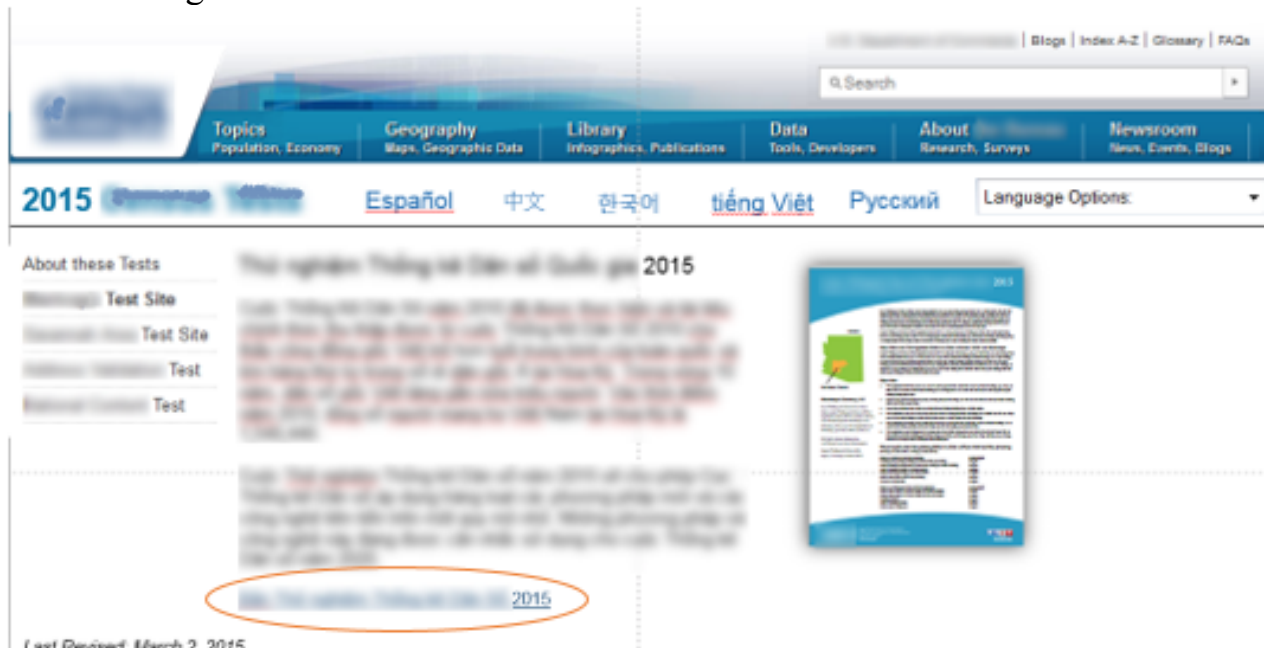

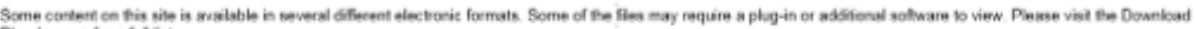

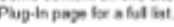

Figure 4. Translated informational web page with a link to the language-specific entry page: Vietnamese ("Web page 3") 
Figure 5 shows an English language informational web page that was mocked up to have five translated tabs beneath the menu bar. When a tab is clicked, it would take users to non-English language content corresponding to the language noted on the tab. To the right of the tabs was a drop-down menu that said "Language Options:". When the downward arrow was clicked on, a list of languages appeared for participants to choose from.

Participants were randomly assigned to two conditions. Half of them $(n=22)$ were assigned to a control condition where the mock-up web page (Figure 5) included five tabs labelled with the name of each language in its native language characters. One of the five tabs was in the participant's native language. The other half of the participants $(n=23)$ were assigned to an experimental condition where they saw the same version of the web page but it showed only four translated tabs, with the tab in their native language missing, so that the only translations they saw were non-English languages they did not know. The experiment was designed to assess participants' reactions and behaviors when the translations of the navigational guide (tabs) did not include the language they knew.

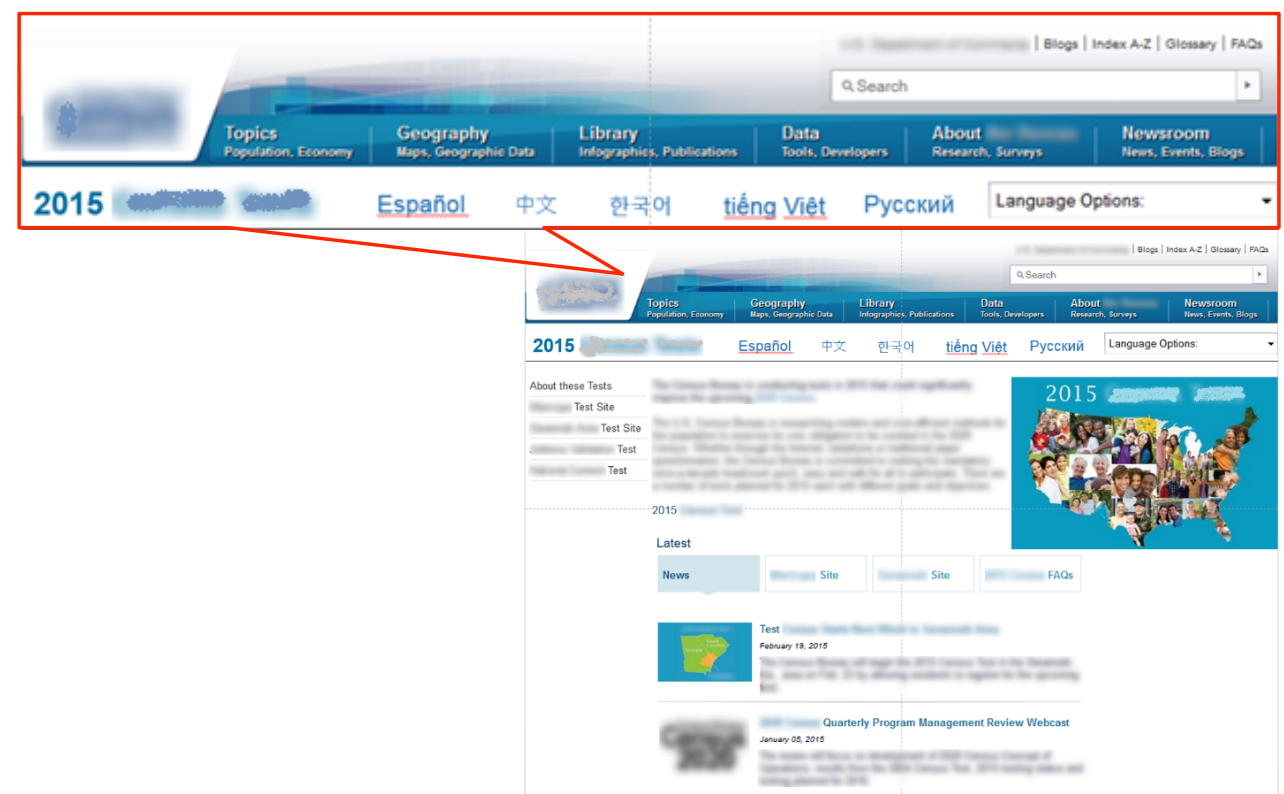

Figure 5. English language informational Website with translated tabs

\section{Results}

\subsection{Prenotification mailing: Multilingual postcard}

Table 1 summarizes what language the participants said they expected to encounter on the survey website based on their reading of the postcard (Figure 1). Even though the postcard message was available in their native language, that did not seem to communicate to all participants that the survey entry page would provide Chinese, Korean, or Vietnamese content. While nine participants believed a translation would be available, twenty participants expected an English-only survey website. Many reasoned that since the URL was in English letters, the website must also be in English. Four participants believed there might be some type of way for them to get to non-English language content, such as through a "language button". Ten other respondents indicated that they expected 
to see a survey website with bilingual content. For example, one Chinese participant envisioned a survey website that is 中英对照 (i.e. bilingual in Chinese and English) because the postcard included both English and Chinese.

Table 1: Participant expectation of the survey website language based on postcard content

\begin{tabular}{l|cccc}
$\begin{array}{c}\text { Language of } \\
\text { interview }\end{array}$ & $\begin{array}{c}\text { Expected } \\
\text { translation }\end{array}$ & $\begin{array}{c}\text { Expected English } \\
\text { and translation }\end{array}$ & $\begin{array}{c}\text { Expected } \\
\text { English only }\end{array}$ & Total \\
\hline Chinese & 1 & 3 & 5 & $9^{*}$ \\
Korean & 2 & 4 & 9 & 15 \\
Vietnamese & 6 & 3 & 6 & 15 \\
Total & 9 & 10 & 20 & 39
\end{tabular}

*There were 15 Chinese speakers, but six did not provide a codable response in this part of the assessment.

\subsection{Survey entry pages}

As described previously, this assessment included three types of survey entry pages:

- Web page 1: Primary survey entry page (Figure 2)

- Web page 2: Language-specific survey entry page (Figure 3)

- Web page 3: Translated information web page with a link to languagespecific survey entry page (Figure 4)

Table 2 shows that for each web page, the majority of the participants ( 39 for web page 1, 39 for web page 2, and 40 for web page 3 ) recognized at least one, if not all, of the visual cues - hyperlinks, tabs, and dropdown menu - which are website functionality visual cues used on websites of any language. They made statements that demonstrated their understanding, for example that hyperlinks are "underlined" and their colours change. In turn, they understood that they could click on the translated hyperlink to respond to the survey in their language.

As shown in Table 3, the majority of the participants clicked on the hyperlink in their native language in web pages 1 and 2 (30 and 33, respectively). They said that it was because they only knew their native language, or that they felt most comfortable getting online information in their native language. Even two Korean participants who reported that they had very limited online experience (and who said that they didn't recognize the visual cue of hyperlinks in Table 2) clicked on the Korean hyperlink that said the name of the survey in web page 1. They explained that the Korean hyperlink was noticeable, and was in Korean so they understood what it was about. However, a key point that arose is that it is not enough just to have translated text on the screen: it also has to catch the eye of respondents. For example, a Korean-speaking participant indicated that she would click on whichever hyperlink was in the centre of the screen because it was more attention catching. Following this logic, she said she would click on the English hyperlink on web page 1 and the Korean hyperlink on web page 2. In terms of web page 3, which was translated in its entirety, all participants clicked on the translated hyperlink leading to the survey (except for three participants who said they did not know what to do due to limited online experience). 
Table 2: Recognition of visual cues on each web page regardless of language of the web page

\begin{tabular}{l|c|c|c}
\hline \multicolumn{1}{c|}{ Behaviours } & Web page 1 & Web page 2 & Web page 3 \\
\hline Recognized visual cue & 39 & 39 & 40 \\
Did not recognize visual cue & 5 & 4 & 3 \\
Total $^{*}$ & 44 & 43 & 43 \\
\hline
\end{tabular}

Table 3: Behaviours toward English and translated hyperlinks

\begin{tabular}{|c|c|c|c|}
\hline Behaviours & Web page 1 & Web page 2 & Web page 3 \\
\hline $\begin{array}{l}\text { Only clicked on translated } \\
\text { hyperlink }\end{array}$ & 30 & 33 & 40 \\
\hline $\begin{array}{l}\text { Only clicked on English } \\
\text { hyperlink }\end{array}$ & 7 & 3 & \\
\hline $\begin{array}{l}\text { Clicked on two hyperlinks, in } \\
\text { English and the translation }\end{array}$ & 4 & 3 & \\
\hline $\begin{array}{l}\text { Did not know how to } \\
\text { navigate the screen }\end{array}$ & $3^{* *}$ & 4 & 3 \\
\hline Total $^{\star}$ & 44 & 43 & 43 \\
\hline
\end{tabular}

In addition, a group of participants clicked on the English hyperlink or clicked on both English and the hyperlink in their native language. As shown in Table 3, seven participants on web page 1 and three participants on web page 2 only clicked on the English hyperlink. Four participants on web page 1 and three participants on web page 2 clicked on both the English hyperlink and the hyperlink in their native language. We found that many of these participants understood all of the words in the hyperlink "Begin survey name", or the key words, such as "Begin". For example, a Vietnamese participant pointed to the English hyperlink "Begin survey name" on web page 1 and said he would click this English hyperlink, because it had the word "begin". But after that he would click on the Vietnamese hyperlink further down the screen on the same web page 1. Another Korean-speaking participant (who understood the visual cue of hyperlinks) assumed the Korean hyperlink on Website 1 was not active because it only stated the name of the survey but did not explicitly say "click here" (여기를 클릭). Based on this assumption, she only clicked on the English hyperlink even though she knew she would not be able to answer the survey in English. This type of behaviour might lead to non-completion if a person is sent to too many irrelevant or confusing web pages.

\subsection{Informational web page with translated tabs}

Seeing Figure 5, all but one participant thought the visible (translated) name of the language shown on the tabs meant that they would be able to get information in that language once they clicked on the tab. The interview excerpt below illustrates how intuitive the Chinese tab was to a participant when he was looking for translated content in Chinese.

Participant: [Pointing to the Chinese tab] I would click the language tab 中文 [Chinese] to find more information because I understand Chinese. 
Interviewer: Did you notice that there are some language labels? What do you think they are for?

Participant: To let people select what [languages] they need to understand the Website.

In the experiment there were some differences between what the two groups said they would do to locate translated content in their native language. As shown in Table 4, all participants in the control condition, whose version had a visible tab in their language, clicked on the tab in their native language. They did not use the drop-down menu or other visual cues on the Website to navigate to the translated content. The participants in the experimental condition, on the other hand, used completely different navigation strategies. Table 5 shows that they did not click on any of the tabs. Although this might not be surprising given that the experiment was designed without displaying a tab in their native language, it showed that rather than randomly clicking on the tab of a language they did not know, they tried searching for other cues to get to translated content in their own language. Without a native language tab they could use, the majority of the experimental group participants (14 of 22) clicked on the drop-down menu next to the tabs to get to translated content. One of them was a Korean-speaking participant whose immediate reaction was to say to herself 한국말이 없네? ("there is no Korean, huh?"), and then move her finger to the "Language Options" dropdown box to look for Korean. In addition, four participants in the experimental condition followed other visual cues on the web page in the absence of an easily accessible Korean tab. One of them was a Vietnamese speaking participant who said she would try all the visual cues she could find on the web page: the search box above the menu bar, other hyperlinks, and the drop-down menu. The interviewer's notes described her attempts:

The participant pointed to "search" and said that she would first click on "search" to find Vietnamese. If she could not find anything, she would try to click on the map picture with people in it. If she still could not find a Vietnamese page, she would click on "Language options" to check if Vietnamese was included in the options.

Table 4: Participants' navigation strategies in the presence of a tab labelled in their native language (control group)

\begin{tabular}{l|ccccc}
$\begin{array}{c}\text { Strategies to } \\
\text { get translated } \\
\text { content: }\end{array}$ & $\begin{array}{c}\text { Clicked on a } \\
\text { tab in their } \\
\text { native } \\
\text { language }\end{array}$ & $\begin{array}{c}\text { Used drop- } \\
\text { down menu }\end{array}$ & $\begin{array}{c}\text { Used non- } \\
\text { language } \\
\text { visual cues }\end{array}$ & $\begin{array}{c}\text { Did not know } \\
\text { what to do }\end{array}$ & Total \\
\hline $\begin{array}{l}\text { Chinese } \\
\text { Korean }\end{array}$ & 6 & 0 & 0 & 0 & 6 \\
Vietnamese & 6 & 0 & 0 & 0 & 6 \\
Total & 8 & 0 & 0 & 0 & 8 \\
& 20 & 0 & 0 & 0 & $20^{*}$
\end{tabular}

*The total is 20 because two of the 22 participants assigned to the control group did not provide a codable response. They were one Chinese-speaking and one Korean-speaking participant. 
Table 5: Participants' navigation strategies in the absence of a tab labelled in their native language (experimental group)

\begin{tabular}{|c|c|c|c|c|c|}
\hline $\begin{array}{l}\text { Strategies to } \\
\text { get translated } \\
\text { content: }\end{array}$ & $\begin{array}{l}\text { Clicked on a } \\
\text { tab not in } \\
\text { their native } \\
\text { language }\end{array}$ & $\begin{array}{l}\text { Used drop- } \\
\text { down } \\
\text { menu }\end{array}$ & $\begin{array}{l}\text { Used other } \\
\text { visual cues } \\
\text { (not tabs or } \\
\text { drop-down) }\end{array}$ & $\begin{array}{l}\text { Could not } \\
\text { figure out how } \\
\text { to get to the } \\
\text { translated } \\
\text { content }\end{array}$ & Total \\
\hline Chinese & 0 & 5 & 0 & 2 & 7 \\
\hline Korean & 0 & 5 & 1 & 2 & 8 \\
\hline Vietnamese & 0 & 4 & 3 & 0 & 7 \\
\hline Total & 0 & 14 & 4 & 4 & $22^{*}$ \\
\hline
\end{tabular}

In addition, four participants in the experimental group - those whose language was not included on a tab - could not figure out how they would get to translated content from Website 3, and ultimately gave up. This did not happen among participants in the control group because they all noticed and clicked on the tab in their native language.

When participants from both groups were asked about whether they had noticed the drop-down menu next to the tabs, about half $(n=21)$ had not. But once it was pointed out to them, most knew its purpose or figured it out - i.e. that they could click on it and there would be options about languages to choose from. A few participants specifically mentioned clicking on the downward arrow. Despite this visual cue, some research participants said that they would not use the dropdown menu unless it was clear to them that they could get to translated content there, as illustrated by an interviewer's notes about a Chinese participant:

The participant said she might be curious and casually click to see "what is in the drop-down menu". However, she also said she probably would not want to click on the menu since she suspects there could still be English materials in the menu.

\section{Discussion}

The results of this assesment show that combining translation with common website functionality visual cues (tabs, hyperlinks, drop-down menus, and URLs) can help limited English-speaking individuals improve their experience using and accessing entry pages and informational web pages for government surveys. For example, we tried a design where language tabs (Figure 5) were labeled with the name of the language in native characters, and this design was successful in guiding participants to click on their respective languages. Among the three entry pages the research participants saw, most of the participants were able to locate and click on the non-English hyperlink even when the primary entry page was in English (web page 1) or when an English hyperlink was embedded in the nonEnglish entry page (web page 2). When the web page was fully translated (web page 3), all participants clicked on the hyperlink in their respective native language.

When a visual cue was clear, but not matched with a clear translation, this was not very helpful in engaging the individuals who speak limited English. For example, on the primary entry page (Figure 2), some participants did not click on the hyperlink in their native language because the hyperlink did not explicitly say to click there. Instead, they clicked on the English hyperlink because it said "begin" and they recognized that word. When using a drop-down menu, if it was not clear 
that the drop-down menu contained translated content, limited English speaking individuals might not click on it even though they recognized it as a visual cue that could possibly lead to more information in their language. In addition, the tabs provided a useful visual cue and were noticeable, but when the participant's language was not written on one of the tabs, limited English speaking participants searched for additional visual cues to get to the translated content and some gave up because they did not know what to do.

Our findings also suggest that translation can only achieve the parameters determined by the English source text and design. For example, the postcard's multi-language translations contained the same messages about participating in the survey as did the English version. The English message did not state that the questionnaire was translated and therefore this information was not reflected in the translation. This led to some participants (logically) assuming that the questionnaire was only in English, and they might therefore be less motivated to go to the website to $\log$ in and participate. In addition, in the primary entry page (Figure 2), the non-English hyperlinks were placed toward the bottom half of the screen and the wording contained in the hyperlinks did not encourage the participants to click on them. As a result, some participants clicked on the English hyperlink because they saw it right away across the screen and did not look further down to locate the non-English hyperlink in their native language. Others were encouraged by the word "begin" in the English hyperlink, which was not included in the non-English hyperlinks. These results suggest that when a translation is present, individuals who speak limited English might not access it if the visual cues associated with the translation are not very noticeable or the directions are not explicit. Both of these possible hidden barriers stem from maintaining the English source text content and design in the non-English languages, and not necessarily because the translation itself is poor.

\section{Conclusion and limitations}

This paper addresses the role of translation and website functionality's visual cues to facilitate limited English speakers' entry to U.S. Federal government Internet surveys. Results from our assessment of translation and visual cues in prenotification materials, mock survey entry pages, and informational web pages suggest the following optimal approach: presenting translation and visual cues together in a visible, clear, and linguistically appropriate way (and culturally appropriate way, as shown in using symbols such as directional arrows that are understood by most people).

There are several limitations. First, six of the 45 participants spoke better English than the rest of the group and it was not clear if they reacted differently to the mock web pages. Their English proficiency might suggest that they were more used to interacting with English-language web pages, thus being more accustomed to their functionalities. Second, we were unable to use live websites and their web pages; instead we had participants look at paper mock ups and describe what they would do. Future research should conduct a full empirical assessment using live websites and their web pages. Third, we did not screen for the participants' Internet proficiency and therefore could not conduct detailed analysis on whether participant behaviours were influenced by their limited or frequent Web experience. For people who use Internet as part of their daily routines, accessing government services and information via the Web may be an uncomplicated practice. Yet, a segment of the population may still lack the experience, capability, and resources to access government websites and/or complete survey 
questionnaires over the Internet. Future research focusing on usability and access should look into Internet usage among limited English speakers and discuss whether the online option is the optimal way to survey particular populations, such as older, less digitally-literate populations. Such a study could also explore a cost-benefit analysis on whether it is feasible to bypass the primary English language entry page (sending non-English participants directly to a link in their language) without significantly increasing the cost of printing for prenotification materials and/or needing to predict the language particular households may speak.

This study provides a starting point to contribute to survey methodology and translation literature about increasing meaningful access to e-government information and services to limited English speakers. Additional research on usability and accessibility, such as the future research ideas we have suggested, is much needed to foster easier and faster entry to online survey questionnaires. The ultimate contribution is to achieve greater inclusion of hard-to-reach populations in U.S. Federal data collections.

\section{Acknowledgement}

The authors thank Hyunjoo Park for her contributions to the design, implementation, and reporting of the original project, and acknowledge Mikelyn Meyers and RTI International interviewers. We also thank Joanne Pascale, Dorothée Behr, Paul Beatty, and Keith Woodling for providing review of this article.

\section{References}

Aldrich, D., Bertot, J. C., \& McClure, C. R. (2002). E-Government: initiatives, developments, and issues. Government Information Quarterly, 19(4), 349355. DOI:https://doi.org/10.1016/S0740-624X(02)00130-2

Behr, D., \& Shishido, K. (2016). The translation of measurement instruments for cross cultural surveys. In C. Wolf, D. Joye, T. W. Smith, \& Y.C. Fu (Eds), The SAGE handbook of survey methodology (pp. 269-287). Thousand Oaks, CA: Sage Publications.

Bertot, J. C., \& Jaeger, P. T. (2006). User-centered e-government: Challenges and benefits for government Web sites. Government Information Quarterly, 23(2), 163-168. DOI: http://dx.doi.org/10.1016/j.giq.2006.02.001

Crezee, I. H. M., Teng, W., \& Burn, J. A. (2017). Teething problems? Chinese student interpreters' performance when interpreting authentic (cross-)examination questions in the legal interpreting classroom. The Interpreter and Translator Trainer, 11(4), 337-356. DOI: 10.1080/1750399X.2017.1359756

Goerman, P. L., \& Caspar, R. A. (2010a). A preferred approach for the cognitive testing of translated materials: Testing the source version as a basis for comparison. International Journal of Social Research Methodology, 13(4), 303-316.

Goerman, P.L., \& Caspar, R. (2010b). Managing the cognitive pretesting of multilingual survey instruments: A case study based on the pretesting of the U.S. Census Bureau Bilingual Spanish/English Questionnaire. In Harkness, J., M. Braun, B. Edwards, T.P. Johnson, L.E. Lyberg, P. Mohler, B. Pennell, \& T.W. Smith (Eds.), Survey methods in multicultural, multinational, and multiregional contexts. (pp. 75-90). New Jersey: John Wiley \& Sons.

Hargittai, E., \& Hsieh, Y. P. (2013). Digital Inequality. In W. H. Dutton (Ed.), The Oxford Handbook of Internet Studies (pp. 129-150). Oxford, UK.: Oxford University Press. 
Harkness, J. A. (2003). Questionnaire translation. In J. A. Harkness, F. J. R. van de Vijver, \& P. P. Mohler (Eds.), Cross-cultural survey methods (Vol. 325, pp. 35-56). Hoboken, NJ: Wiley-Interscience.

Harkness, J. A., Villar, A., \& Edwards, B. (2010). Translation, adaptation, and design. In J. A. Harkness, M. Braun, B. Edwards, T. P. Johnson, L. Lyberg, P. P. Mohler, B. E. Pennell, \& T. W. Smith (Eds.), Survey methods in multinational, multiregional, and multicultural contexts (pp. 117-130). Hoboken, NJ: John Wiley \& Sons.

Helbig, N., Gil-García, J. R., \& Ferro, E. (2009). Understanding the complexity of electronic government: Implications from the digital divide literature. Government Information Quarterly, 26(1), 89-97. DOI:http://dx.doi.org/10.1016/j.giq.2008.05. 004

Jaeger, P. T. (2006). Assessing Section 508 compliance on federal e-government Web sites: A multi-method, user-centered evaluation of accessibility for persons with disabilities. Government Information Quarterly, 23(2), 169-190. DOI: http://dx.doi. org/10.1016/j.giq.2006.03.002

Limited English Proficiency (LEP). A Federal Interagency Website. Retrieved 11/12/2017 from https://www.lep.gov

Neuhauser, L., Rothschild, R., \& Rodríguez, F. M. (2007). MyPyramid.gov: Assessment of Literacy, Cultural and Linguistic Factors in the USDA Food Pyramid Web Site. Journal of Nutrition Education and Behavior, 39(4), 219-225. DOI: http://dx.doi.org/ 10.1016/j.jneb.2007.03.005

Nord, Ch. (1997). Translating as a purposeful activity. Manchester: St. Jerome.

Olalere, A., \& Lazar, J. (2011). Accessibility of U.S. federal government home pages: Section 508 compliance and site accessibility statements. Government Information Quarterly, 28(3), 303-309. DOI: http://dx.doi.org/10.1016/j.giq.2011.02.002

Pan, Y., \& de la Puente, M. (2005). Census Bureau guideline for the translation of data collection instruments and supporting materials: Documentation on how the guideline was developed. Survey Methodology, 6. Retrieved from https:/www. census.gov/srd/papers/pdf/rsm2005-06.pdf

Reiss, K., \& Vermeer, H. J. (1984). Towards a general theory of translational action. Manchester: St. Jerome.

Ryan, C. (2013). Language use in the United States: 2011. Retrieved from https://www.census.gov/prod/2013pubs/acs-22.pdf

Selden, S., \& Orenstein, J. (2011). Government e-recruiting web sites: The influence of erecruitment content and usability on recruiting and hiring outcomes in US state governments. International Journal of Selection and Assessment, 19(1), 31-40. DOI: 10.1111/j.1468-2389.2011.00532.x

Sha, M., \& Pan, Y. (2013). Adapting and improving methods to manage cognitive pretesting of multilingual survey instruments. Survey Practice, 6(4), 1-8.

Social Security Administration (SSA). Homepage. Retrieved 11/12/2017 from https:// www.ssa.gov/site/languages/en/

Social Security Administration (SSA). Social security information in other languages. Retrieved 11/12/2017 from https://www.ssa.gov/site/languages/en

Taibi, M., \& Ozolins, U. (2016). Community Translation. London/New York: Bloomsbury Academic.

Teng, W., Burn, J. A., \& Crezee, I. H. M. (2018). I'm asking you again! Chinese student interpreters' performance when interpreting declaratives with tag questions in the legal interpreting classroom. Perspectives: Studies in Translation Theory and Practice, 22(3), 321-331. DOI: 10.1080/0907676X.2018.1444071

US Census Bureau. (2016). Press Release Number: CB16-107 (June 23). Retrieved 11/12/2017 from https://www.census.gov/newsroom/press-releases/2016/cb16-107. html

US Census Bureau. (n.d.-a.). United States Census 2010. Retrieved 11/12/2017 from https://www.census.gov/programs-surveys/decennial-census/decade/2010/about2010.html

US Census Bureau. (n.d.-b.). American Fact Finders Glossary. Retrieved 5/29/2018 from https://factfinder.census.gov/help/en/index.htm\#glossary.htm 
US Citizenship and Immigration Services (USCIS). (n.d.). Homepage. Retrieved 11/12/2017 from https://www.uscis.gov

US Department of Homeland Security. (n.d.). Ready. Languages. Retrieved 11/12/2017 from https://www.ready.gov/languages

USA.gov. (n.d.) Homepage. Retrieved 11/12/2017 from https://www.usa.gov

Verdegem, P. \& Verleye, G. (2009). User-centered E-Government in practice: A comprehensive model for measuring user satisfaction. Government Information Quarterly, 26(3), 487-497. DOI: http://dx.doi.org/10.1016/j.giq.2009.03.005

West, D. M. (2006). The digital divide in public e-health: Barriers to accessibility and privacy in state health department websites. Journal of Health Care for the Poor and Underserved, 17(3), 652-667.

White House Initiative on Asian Americans and Pacific Islanders. (n.d.). Language access. Retrieved 11/12/2017 from https://sites.ed.gov/aapi/language-access 